\title{
Using Nursing Interventions Classification as a Framework to Revise the Belgian Nursing Minimum Data Set
}

Koen Van den Heede, PhD, RN, Dominik Michiels, Msc, RN, Olivier Thonon, Msc, RN, and Walter Sermeus, PhD, FEANS, RN

PURPOSE. To develop the revised Belgian nursing minimum data set (B-NMDS). METHODS. The Nursing Interventions Classification (NIC, 2nd edition) was used as a framework. Six expert nurse panels (cardiology, oncology, intensive care, pediatrics, geriatrics, chronic care) were consulted. Seventy-nine panelists completed standardized e-mail questionnaires and discussed results in face-to-face meetings.

FINDINGS. We initially selected 256 of 433 NIC interventions. After panel discussions, plenary meetings, and pretesting, the revised B-NMDS (alpha version) contained 79 items covering 22 NIC classes and 196 NIC interventions. CONCLUSIONS. Consensus building promoted acceptance of the B-NMDS, while the NIC provided a good theoretical basis and guaranteed international comparability.

IMPLICATIONS FOR NURSING PRACTICE. The revised B-NMDS instrument can be used to visualize nursing activities in different applications (e.g., financing, staffing allocation).

Search terms: Consensus building, Nursing Interventions Classification (NIC), nursing minimum data set (NMDS)

doi: 10.1111/j.1744-618X.2009.01124.x
DOELSTELling. Ontwikkeling van een nieuwe versie van de Minimale Verpleegkundige Gegevens (MVG).

METHODE. De Nursing Interventions

Classification (NIC, 2nd editie) werd gebruikt als raamwerk. Zes experten panels (cardiologie, oncologie, intensieve zorgen, pediatrie, geriatrie, chronische zorg) werden geraadpleegd.

Zeven-en-negentig panelleden vulden gestandaardiseerde e-mail vragenlijsten in en bediscussieerden de resultaten in werkgroepvergaderingen.

RESULTATEN. We selecteerden initieel 256 van de 433 NIC-interventies. Na panel-discussies, plenaire vergaderingen, en pre-tests, bevatte de herziene MVG (alpha versie) 79 items uit 22 NIC klassen en 196 NIC-interventies. CONCLUSIES. Het draagvlak voor de herziene versie van MVG werd gecreëerd door het nastreven van consensus. Het gebruik van NIC vormde hierbij een geode theoretische basis en verhoogt het internationaal karakter van de nieuwe $M V G$.

IMPLICATIES VOOR DE VERPLEEGKUNDIGE PRAKTIJK. De nieuwe MVG kan gebruikt worden om de dagelijkse verpleegkundige praktijk zichtbaar te maken in verschillende beleidsdomeinen (e.g., financiering, toewijzing personeel).

Zoektermen: Nursing Interventions Classification (NIC), Minimale Verpleegkundige Gegevens, ontwikkeling van consensus 
Koen Van den Heede, PhD, RN, is Research Fellow at the Centre for Health Services and Nursing Research, Katholieke Universiteit and Staff Member of the Nursing Competence Center, University Hospitals Leuven, Leuven, Belgium; Dominik Michiels, Msc, RN, is Care Program Manager, General Management, University Hospitals Leuven, Leuven, Belgium; Olivier Thonon, Msc, RN, is Nurse Manager and Research Fellow of the Medical and Economical Information Department, University Hospital of Liège, Liège, Belgium; and Walter Sermeus, PhD, FEANS, RN, is Professor and Program Director, The Centre for Health Services and Nursing Research, Katholieke Universiteit Leuven, Leuven, Belgium.

I Internationally, healthcare agencies use cost-cutting strategies such as shortening length of stay and increasing the numbers of 1-day hospitalizations to stem exploding healthcare costs (Schubert et al., 2008). Because nursing is the largest professional group which provides direct care, there is a compelling need for the nursing profession to demonstrate to the general public as well as to other healthcare professionals and policy makers what exactly nurses do. One way to visualize nursing care is to use nursing minimum data sets (NMDS). Although the international nursing community recognizes the necessity of NMDS (Goossen, Delaney, \& Coenen, 2005), the only country that has implemented NMDS data on a widespread scale is Belgium (Mac Neela, Scott, Treacy, \& Hyde, 2006).

Since 1988, the Belgian Ministry of Public Health has randomly sampled nursing activity during 5 days within the first 15 days of March, June, September, and December. On these days, hospitals collect nurse staffing patterns and nursing care activity data. These data are commonly known as the national Belgian NMDS (B-NMDS). First, for every patient admitted to inpatient hospitalization units or 1-day clinics, a list of 23 nursing interventions is scored. Second, for each nursing unit where these patients are treated, the number and qualifications of nursing staff directly involved in patient care is recorded (Sermeus, Delesie, Van den Heede, Diya, \& Lesaffre, 2008). Twenty years of registration has resulted in a unique database that contains information about nursing care, covering more than 18 million inpatient days. This information is used by hospital managers to support decisions regarding nurse staffing allocation and by the Ministry of Public Health to allocate about $6.5 \%$ of the overall hospital budget to hospitals.

Nursing care has changed drastically since 1988. Thus, starting January 2008, all Belgian acute hospitals have implemented a revised B-NMDS. This paper describes the process used to revise the 23-item B-NMDS to form the revised B-NMDS (alpha version). In the first phase (2002-2004), the Ministry of Public Health commissioned a research team to revise the B-NMDS for only six care programs-geriatric care, chronic care, pediatric care, intensive care, oncology, and cardiology. In the second phase (2005-2006), the revision of the B-NMDS was broadened to include general surgical care, internal medicine, 1-day clinics, and maternity care. This paper only describes the revision process involving the first six care programs.

The revision process had two foci: (a) building recent international nursing language developments, and (b) building national professional consensus. Addressing the first foci required that the revised B-NMDS be based on a standardized international language. When the original B-NMDS was developed in 1983, a standardized international nursing language did not exist. Thus, the content of the original B-NMDS was based only on professional consensus and statistical criteria derived from empirical tests (Delesie, De Becker, \& Sermeus 1986). The content of the B-NMDS is therefore specific to the Belgian context, which limits its potential for international comparisons. Based on a narrative literature review (Sermeus et al., 2006), the most frequently cited nursing languages were the Nursing Interventions Classification (NIC) (McClosky et al., 1996), the International Classification for Nursing Practice (International Council of Nurses, 1999), the Home Health Care Classification or Clinical Care Clas- 
Using Nursing Interventions Classification as a Framework to Revise the Belgian Nursing Minimum Data Set

sification System (Saba, 2007), and the Omaha System (Martin \& Scheet, 1992). For the B-NMDS revision, we chose the NIC (2nd edition) as a framework for five main reasons: (a) the NIC is an internationally accepted nursing language (i.e., incorporated into the National Library of Medicine Metathesaurus of Unified Medical Language); (b) the NIC is research based; (c) the NIC covers all fields of nursing; (d) the NIC undergoes systematic revisions; and (e) the NIC is logical from a clinical point of view (i.e., developed inductively from nursing clinical practice, and NIC domains, classes, and interventions are used in daily nursing practice). In addition, the NIC is available in two official Belgian languages (Dutch and French) and has been previously investigated in Belgian home health care (De Vliegher et al., 2005).

The second principle, building national professional consensus, involves the Belgian healthcare sector. Building national professional consensus is an important component of this project, as successful national implementation of the revised B-NMDS requires national consensus. Ignoring this second principle can be one of the explanations why the NMDS initiatives outside of Belgium have failed. The detailed description of both principles makes this data applicable to the international community and can provide information for similar initiatives in other countries.

\section{A Comparison of NIC and B-NMDS}

The NIC is a nursing language that provides a standardized and unambiguous method to document and describe nursing activities that are performed or should be performed (McClosky et al., 1996). The NIC facilitates communication through labels and definitions which ensure that users fully understand pertinent concepts.

There are three main differences between the NIC and the B-NMDS. First, unlike the NIC, the B-NMDS is not a pure language. Rather, it is more of a data collection instrument that measures phenomena in an unambiguous way. Therefore, including items into the
B-NMDS requires adherence to stringent inclusion and exclusion criteria. In addition, the registration of nursing activities in the B-NMDS is linked to specific criteria that allow the Ministry of Public Health to perform external audits-e.g., Is the coded nursing activity documented in the patient record? Second, the B-NMDS includes only direct nursing care activities, while the NIC includes both direct and indirect nursing care activities. Third, the NIC is limited to interventions that follow a nursing or medical diagnosis. Nursing activities such as "assessment" are not well covered by the NIC. Assessment is part of the nursing diagnostic process which is covered by the North American Nursing Diagnosis Association International (NANDA-I, 2009). In the present study, we describe the process of transforming NIC language for use in a B-NMDS registration instrument.

\section{Methods}

\section{Expert Panels}

We recruited a panel of 12 experts for each of the six care programs, cardiology, oncology, intensive care, pediatrics, geriatrics, and chronic care (i.e., 72 experts in total). During a national conference for nurse directors organized by the Ministry of Public Health at the start of the project (September 2002), all hospitals were invited to recommend candidates from their institution with clinical expertise in the six care programs. This resulted in 129 applications. Based on specific criteria (i.e., type of hospital, size of hospital, geographical region, illustrated expertise), representatives of the Ministry of Public Health, in collaboration with the research team, selected at least six Dutch-speaking and six French-speaking experts for each of the six panels. Our aim was to compose each panel such that each contained a majority of ward managers and clinical nurse specialists (because of their clinical expertise), some nurses with middle management positions (for their management expertise), and some B-NMDS coordinators (for their experiences with the original 
B-NMDS). The final panels included 79 experts from 65 different hospitals (53\% of all Belgian hospitals). Of the 79 panelists, $73 \%$ were ward managers and clinical nurse specialists, $14 \%$ were nurses with middle management positions and were B-NMDS coordinators, and $13 \%$ were professionals holding other positions.

A steering committee composed of representatives from the Ministry of Public Health, acute hospitals, professional nursing organizations, and the research community was appointed by the Ministry of Public Health and met at crucial steps during the project. The role of this committee was to monitor the study progress, and, if necessary, to report project plan problems to the Ministry of Public Health.

\section{From Nursing Classification to NMDS Registration: Expert Panel Meetings}

From December 2002 to June 2003, the six expert panels convened at least six times. All panel meetings were bilingual (French and Dutch). Panels received assignments from the research team (a researcher was assigned to two panels). The main aim of the expert panels was to select and transform NIC interventions into a revised B-NMDS instrument. To guide this selection process, each member of each expert panel was asked to rank, in order of importance, 11 potential applications for the revised B-NMDS. The 11 applications were derived from a literature review and included assessing appropriateness of hospitalization, benchmarking nursing care, differentiated nursing practice, electronic nursing record development, epidemiology, hospital financing, internal hospital administration applications, nursing education curriculum planning, nursing research, staffing allocation, and quality of care (Sermeus et al., 2006). Because the B-NMDS registration increases the workload of already overworked bedside nurses, a registration was deemed to be justified only when it is linked to specific exploration of the data.

Each panel member was asked to use a priority list of future applications to answer two questions regard- ing the 433 interventions of the NIC (2nd edition) (McClosky et al., 1996) using the most recent NIC version available in Dutch and French at the time of the study. The questions were: (a) is this NIC intervention frequently present in your clinical practice? and (b) is this NIC intervention relevant for the revised B-NMDS (in light of the 11 applications)? The first question was used to gather information about the core interventions of the specific care programs. At the same time, the first question also stimulated the respondents to provide more selective responses to the second question. The second question was used to select only core interventions pertinent to prospective applications of the revised B-NMDS. Panelists received a guide containing instructions and definitions of each NIC intervention.

Next, the panelists selected which NIC interventions would be incorporated into the revised B-NMDS. An NIC intervention was selected if the majority of panelists on at least one of the six panels selected the intervention. If a majority was not achieved for any given intervention, a panel discussion was convened until consensus about selecting the intervention was achieved. The selected NIC interventions were then transformed into B-NMDS items. If the selected NIC interventions matched corresponding items of the original B-NMDS, then these items were used as a starting point for the discussions. The research team proposed new B-NMDS items for NIC interventions that did not correspond to the original B-NMDS. For each item, the research team drafted a definition (with inclusion and exclusion criteria), response categories, and data control requirements (i.e., the required minimal clinical documentation in the patient record to justify the presence of this nursing intervention when the registration is audited). All original and newly proposed B-NMDS items that corresponded to NIC interventions selected by a particular expert panel were discussed thoroughly by that expert panel. During these sessions, the experts also commented on all draft versions of the revised B-NMDS items. Subsequently, the research team redrafted the items at least twice in 
Using Nursing Interventions Classification as a Framework to Revise the Belgian Nursing Minimum Data Set

order to obtain a final draft of the revised items to be reviewed by each expert panel. During this process the research team used standard questions to guide the panel meetings (see Box 1).

\section{Box 1. Questions Posed to Guide the Expert Panel Meetings}

\section{Definitions}

What are the minimal requirements for this intervention?

Is this intervention evidence based?

Response categories

Does a score of 2 for a particular item imply more intensive care than a score of 1 ?

Is it necessary to measure this kind of detail?

Controls

What clinically relevant information should be documented in patient records for this intervention?

Is it appropriate to ask nurses to document this kind of information in patient records?

On the basis of the outcome of each expert panel, the research team drafted a first version of the revised B-NMDS instrument and presented it at a plenary session of a special meeting attended by the six expert panels and the steering committee in June of 2003. After the plenary session, each expert panel discussed the revised B-NMDS draft during breakout sessions. The primary purpose of these sessions was to determine whether the concerns, comments, and suggestions made by each panel in previous sessions were reflected in the proposed instrument. At the end of the day, a representative from each panel presented the plenary remarks of his particular expert panel.

During the next 2 months, the 79 expert panel members were invited to forward their comments on the first draft of the revised instrument to the research team. The research team redrafted the instrument based on comments that were made by more than one member. The ensuing second draft was then subjected to a pretest.

The aim of the pretest was to assess the feasibility and to identify inconsistencies, lack of clarity in definitions, response categories, and control requirements of the revised B-NMDS instrument. We invited the experts to participate in the pretest, and based on three criteria, being a ward manager or clinical nurse specialist, consent of hospital administration, and balanced geographical distribution, a convenience sample was established consisting of 25 nursing units in 15 different hospitals. Together with an expert panel member, the research team scored at least two patient records per nursing unit. If information from the patient record was insufficient, the staff nurse responsible for the patient was questioned. Based on the pretest, a final draft of the revised B-NMDS was prepared and e-mailed to all the experts in August of 2003. The final draft was presented to all six expert panels in September of 2003. This was the last meeting in which comments and suggestions were formulated. Based on these final comments, an alpha version of the revised B-NMDS was prepared and then presented to all chief nurse officers (or representatives) of all Belgian acute hospitals during a seminar organized by the Ministry of Public Health to recruit candidate hospitals to pilot test the alpha version. Hospitals that were not represented by one of the six expert panels were also present at this seminar.

\section{Findings}

The results are based on the responses from 64 panelists, which represent $83 \%$ of all panelists, and included 9 in geriatrics, cardiology, oncology, and pediatrics, and 15 in chronic care. The mean rankings of the priority applications are listed in Table 1. The first three applications, staffing allocation, hospital financing, and quality of care, were consistently ranked by most of the panels as the most important applications of the revised B-NMDS. Only the chronic care 
Table 1. Mean Rankings of Potential Applications for the Revised B-NMDS Based on Expert Panel Consultation

\begin{tabular}{|c|c|c|c|c|c|c|c|}
\hline Applications & GEN & CAR & ICU & PED & GER & CHR & ONC \\
\hline Staffing allocation & 3.1 & 2.7 & 3.1 & 3.0 & 2.5 & 4.2 & 2.5 \\
\hline Hospital financing & 3.2 & 3.6 & 3.6 & 2.9 & 2.3 & 2.9 & 3.8 \\
\hline Differentiated nursing practice & 5.7 & 5.2 & 6.0 & 5.4 & 5.0 & 6.2 & 6.3 \\
\hline Assessing appropriateness of hospitalization & 5.8 & 6.3 & 6.9 & 4.9 & 7.8 & 3.8 & 6.0 \\
\hline Internal hospital administration applications & 6.2 & 7.4 & 5.3 & 5.8 & 5.6 & 7.2 & 5.5 \\
\hline Nursing research & 6.8 & 4.9 & 6.6 & 7.6 & 7.1 & 7.8 & 6.5 \\
\hline Nursing education curriculum planning & 8.9 & 9.4 & 8.8 & 9.9 & 8.1 & 9.2 & 7.9 \\
\hline Epidemiology & 9.4 & 9.4 & 9.0 & 9.5 & 9.8 & 8.8 & 9.8 \\
\hline
\end{tabular}

B-NMDS, Belgian nursing minimum data set; CAR, cardiology expert panel; CHR, chronic care expert panel; GEN, all six expert panels combined; GER, geriatric expert panel; ICU; intensive care expert panel; ONC, oncology expert panel; PED, pediatric expert panel.

panel failed to rank staffing allocation as most important. The applications "epidemiology" and "nursing education curriculum planning" were rated by all panels as the least relevant applications.

The panelists selected 256 of 433 NIC interventions as relevant nursing interventions for the revised B-NMDS. All NIC classes were assessed by at least one expert panel (Table 2). The pediatrics experts selected the most nursing interventions (153), while the geriatric care experts selected the fewest nursing interventions (97). Overall, most nursing interventions were selected in NIC domains 1-3 (Table 2). In NIC domain 5, "family," only the pediatric experts selected a substantial number of nursing interventions (e.g., 1052 bottle feeding, 0612 urinary incontinence care, enuresis), while in domain 6, "Health system," it was oncology experts who mainly selected nursing interventions (e.g., 7620 controlled substance checking, 7690 laboratory data interpretation).

The selected NIC interventions were then matched, if possible, to corresponding items of the original B-NMDS, as summarized in Table 3. The NIC interventions selected by the geriatric care panel from class B, "elimination management," matched the original
B-NMDS item "care relating to elimination." Care relating to elimination has four ordinal response categories-(a) no assistance, (b) supportive assistance, (c) partial assistance, and (d) complete assistance-and includes care for both fecal and urinary elimination. The nursing interventions listed in Table 3 can all be scored in terms of the care relating to elimination item (e.g., urinary catheterization corresponds to a score of 4). The matching procedure was discussed in an expert panel meeting. The geriatric care experts provided several comments on the care relating to elimination item. They suggested that care for urinary and care for fecal elimination needed to be clearly differentiated. They also recommended dividing technical activities like "urinary catheterization" and "bowel irrigation" into separate items. They stated that grouping all of these interventions into a single item would hamper registration clarity. The matching procedure for the care relating to elimination item was similarly discussed among the other five expert panels, ultimately resulting in six items for elimination care in the alpha version of the revised B-NMDS (Table 4).

For NIC interventions that did not correspond to an original B-NMDS item, the research team drafted new 
Using Nursing Interventions Classification as a Framework to Revise the Belgian Nursing Minimum Data Set

Table 2. Selection of Relevant NIC Interventions for the Revised B-NMDS per Expert Panel

\begin{tabular}{|c|c|c|c|c|c|c|c|}
\hline NIC domain & MAX & CAR $^{a}$ & $\mathrm{ICU}^{\mathrm{a}}$ & PED $^{a}$ & $\mathrm{GER}^{\mathrm{a}}$ & $\mathrm{CHR}^{\mathrm{a}}$ & $\mathrm{ONC}^{\mathrm{a}}$ \\
\hline \multicolumn{8}{|c|}{ Physiological, basic (1) } \\
\hline Classes $^{\mathrm{b}}$ & $6(\mathrm{~A}-\mathrm{F})$ & 6 & $5(\mathrm{~A})$ & $5(\mathrm{~A})$ & 6 & 6 & 6 \\
\hline \multicolumn{8}{|c|}{ Physiological, complex (2) } \\
\hline Classes & $8(\mathrm{G}-\mathrm{N})$ & $6(\mathrm{I}, \mathrm{M})$ & 8 & 8 & $7(\mathrm{~J})$ & $7(\mathrm{~J})$ & $7(\mathrm{I})$ \\
\hline Interventions & 143 & 73 & 61 & 55 & 31 & 35 & 48 \\
\hline Interventions & 103 & 8 & 4 & 13 & 6 & 18 & 22 \\
\hline \multicolumn{8}{|l|}{ Safety (4) } \\
\hline Classes & $2(\mathrm{U}, \mathrm{V})$ & 2 & 2 & 2 & 2 & $1(\mathrm{U})$ & 2 \\
\hline Interventions & 46 & 10 & 7 & 13 & 10 & 10 & 11 \\
\hline \multicolumn{8}{|l|}{ Family (5) } \\
\hline Classes & $2(W, \quad X)$ & $0(\mathrm{~W}, \mathrm{X})$ & $0(\mathrm{~W}$, & 2 & 0 & $1(W)$ & $1(\mathrm{~W})$ \\
\hline \multicolumn{8}{|l|}{ Overall } \\
\hline Classes & 27 & 18 & 18 & 22 & 22 & 24 & 24 \\
\hline Interventions & 433 & 113 & 99 & 153 & 97 & 116 & 147 \\
\hline
\end{tabular}

${ }^{\text {a }}$ Dropped classes between brackets.

${ }^{b}$ NIC classes: A, activity and exercise management; $B$, elimination management; C, immobility management; D, nutrition support;

E, physical comfort promotion; F, self-care facilitation; $G$, electrolyte and acid base management; $H$, drug management; I, neurologic management; J, perioperative care; $\mathrm{K}$, respiratory management; L, skin/wound management; $\mathrm{M}$, thermoregulation; $\mathrm{N}$, tissue perfusion management; $\mathrm{O}$, behavior therapy; $\mathrm{P}$, cognitive therapy; $\mathrm{Q}$, communication enhancement; $\mathrm{R}$, coping assistance; $\mathrm{S}$, patient education;

$\mathrm{T}$, psychological comfort promotion; $\mathrm{U}$, crisis management; $\mathrm{V}$, risk management; $\mathrm{W}$, childbearing care; $\mathrm{X}$, life span care; $\mathrm{Y}$, health system mediation; $a$, health system management; $b$, information management.

B-NMDS, Belgian nursing minimum data set; CAR, cardiology expert panel; CHR, chronic care expert panel; GER, geriatric expert panel; ICU, intensive care expert panel; MAX, maximum number of interventions or classes; NIC, Nursing Interventions Classification;

$\mathrm{ONC}$, oncology expert panel; PED, pediatric expert panel.

items, fine-tuning the newly proposed items after discussions with the different expert panels. The nursing intervention "1400 pain management," for instance, was transformed into the item "pain management." This item was defined as the "regular, systematic monitoring of a patient's pain by the care provider using a pain scale that has been scientifically validated." The response categories of this item included the "frequency of symptom control." In order to score this item, the patient record needs to include a written customized pain management procedure or needs to include a referral to a standard pain management procedure.

All six expert panels carried out this process. During the discussions, some of the NIC interventions that were initially selected were dropped. Also, we added some nursing activities considered to be important by the expert panels but not reflected in one of the 433 NIC interventions. For the latter group, additional items were developed (e.g., item Z200: functional, mental, and psychosocial evaluation). 
Table 3. NIC Interventions Selected by the Geriatric Expert Panel for NIC Class B

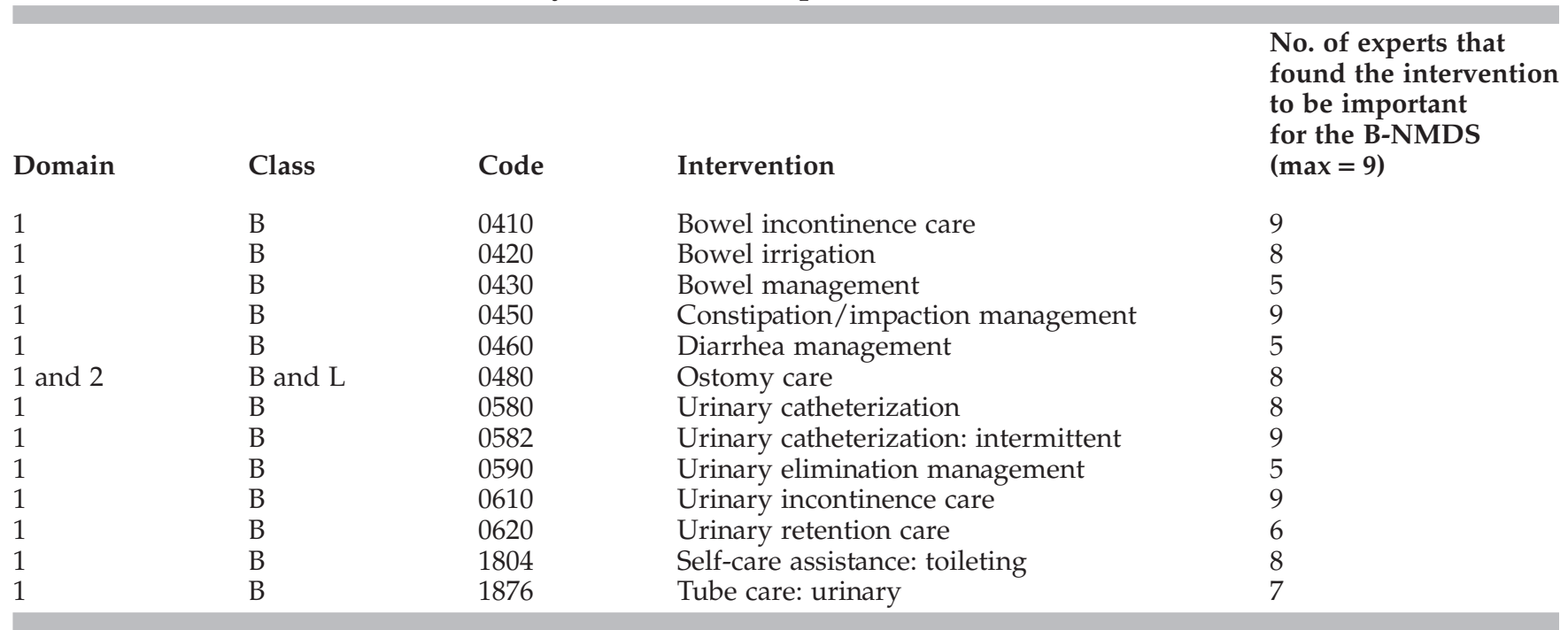

B-NMDS, Belgian nursing minimum data set; NIC, Nursing Interventions Classification.

Finally, not all of the NIC classes were retained within the revised B-NMDS (alpha version). After the expert panel meeting discussions, the pretest, and the validation process, five NIC classes were left blank: class J-perioperative care (the revised B-NMDS will not contain activities performed during operations); class $\mathrm{M}$-thermoregulation (was deemed as too specific); class $\mathrm{T}$-psychological comfort promotion (interventions performed only by nurses in psychiatric nursing units that are not included in the B-NMDS); class U-crisis management (additional registrations for the B-NMDS would be redundant, because crisis management information is already available in standardized medical databases); and class Wchildbearing care (maternity care was not one of the six care programs considered). In the end, the alpha version of the revised B-NMDS included a total of 79 items, representing 196 (45.3\%) NIC items (the instrument is available from the authors upon request).

\section{Discussion}

This paper describes the development of an alpha version of the revised B-NMDS. This instrument was developed using the NIC as a framework. Because the objectives differ between the NIC, a nursing language that facilitates standardized communication, and the B-NMDS instrument, a registration instrument that gathers data for applications in hospital management, healthcare policy, and research, expert panels were consulted to support the research team in developing the revised B-NMDS. This process was an essential first step to make the nationwide implementation of the revised B-NMDS in March 2008 possible.

Carefully selecting the expert panels and incorporating their suggestions and comments in the revised B-NMDS was essential for acceptance of this new instrument by the nursing profession. The approach used in this project produced an instrument comprised of nursing interventions which reflect the daily activi- 
Using Nursing Interventions Classification as a Framework to Revise the Belgian Nursing Minimum Data Set

Table 4. Items of the Revised B-NMDS (Alpha Version) for "Elimination Management" (Based on NIC Class B)

NMDS item (and sub-items)

B100: care linked to elimination in children (under 5)

B200: urinary and/or fecal elimination education

$\mathrm{B}^{* *}$ : care associated with urinary elimination

B310: normal urinary elimination

B320: urinary elimination support for continent patients

B330: care associated with urinary incontinence

B340: care associated with the presence of a urinary ostomy

B350: care associated with the presence of a permanent

vesical catheter

B400: inserting a vesical catheter

Item B5 **: fecal elimination

B510: normal fecal elimination

B520: fecal elimination support for continent patients

B530: care associated with fecal incontinence

B540: care associated with the presence of a fecal ostomy

B600: administration of an enema or manual removal of

fecaliths in order to treat or prevent constipation

\section{Response categories}

(a) Day AND night supervision of elimination in potty-trained children by a care provider

(b) Nighttime supervision of elimination in children who are potty-trained during the day by a care provider outside the context of specific enuresis programs

(c) Care for children who are not potty trained during the day or night, e.g., supervision and regular changing

(a) Presence of urinary education/training

(b) Presence of fecal education/training

(c) Presence of urinary and fecal education/training

Only one of sub-items B310-B350 can be scored

(a) Presence of normal urinary elimination

(a) Supporting assistance

(a) Presence of care associated with urinary incontinence

(a) Care associated with the presence of a urinary ostomy

(a) Care associated with the presence of a permanent catheter

Frequency of insertion

Only one of sub-items B510-B540 can be scored

(a) Presence of normal fecal elimination management

(a) Fecal elimination support for continent patients

(a) Presence of care

(a) Care associated with the presence of a fecal ostomy

(a) Insertion of a rectal cannula and/or administration and an enema and/or removal of fecaliths

B-NMDS, Belgian nursing minimum data set; NIC, Nursing Interventions Classification.

ties of nurses. As a result, this instrument has received support from the nursing profession. To increase an objective selection of NIC interventions, the research team used standardized assignments that had to be returned to the research team via e-mail. However, because the dynamics of expert panels are highly subjective, a large pilot test was also conducted to test the alpha version of the revised B-NMDS (Sermeus et al., 2006).

Using the NIC for revising the B-NMDS has several advantages. First, incorporation of NIC items into the revised B-NMDS has resulted in an instrument that goes beyond the local language, one capable of facilitating communication with the international nursing community. Similar initiatives in other countries that use the NIC can make benchmarking nursing care information available on an international scale. The use of the NIC will also facilitate the development of electronic nursing records and the sequential derivation of B-NMDS data from electronic nursing records. The NIC has already been used as a framework for electronic patient records development (Von Krogh, Dale, \& Naden, 2005).

A limitation of this study is that it is based on the second edition of NIC, which is an outdated version and was used because this was the only version which 
was translated into Dutch and French. To disseminate the use of NIC internationally, there is, thus, a clear need for the "The Center for Nursing Classification and Clinical Effectiveness" to organize a system to produce validated translations that follow shortly after the release of a new NIC edition.

\section{Conclusions}

The recent successful nationwide implementation of the revised B-NMDS illustrates that the approach succeeded. This approach was based on the combination of an objective international framework and a subjective, but extensive, expert consultation. Therefore, it is recommended that new NMDS initiatives should be founded on a sound strategy that builds national consensus within the nursing community. In addition, the overall project plan should include a theoretical framework and empirical testing of the newly developed instrument.

Acknowledgment. This study was funded by the Belgian Ministry of Public Health.

Author contact: koen.vandenheede@med.kuleuven.be

\section{References}

Delesie, L., De Becker, P., \& Sermeus, W. (1986). Pilootstudie registratie minimale verpleegkundige gegevens. Leuven, Belgium: Center for Health Services Research, K. U. Leuven.
De Vliegher, K., Paquay, L., Grypdonck, M., Wouters, R., Debaillie, R., \& Geys, L. (2005). A study of core interventions in home nursing. International Journal of Nursing Studies, 42(5), 513-520.

Goossen, W., Delaney, C., \& Coenen, A. (2005). International nursing minimum data set (iNMDS). In N. Oud, W. Sermeus, \& M. Ehnfors (Eds.), ACENDIO 2005: 5th European conference of Acendio: Documenting nursing care (pp. 31-34). Bern, Switzerland: Verlag Hans Huber.

International Council of Nurses. (1999). The international classification for nursing practice. Geneva, Switzerland: ICN Press.

Mac Neela, P., Scott, P. A., Treacy, M. P., \& Hyde, A. (2006). Nursing minimum data sets: A conceptual analysis and review. Nursing Inquiry, 13(1), 44-51.

Martin, K. S., \& Scheet, N. J. (1992). The Omaha system: Applications for community health nursing. Philadelphia: WB Saunders.

McClosky, J. C., Bulechek, G. M., Craft-Rosenberg, M. C., Daley, J., Denehey, J., \& Glick, O. (1996). Nursing interventions classification (NIC) - Second edition. St. Louis, MO: Mosby.

NANDA-I. (2009). Nursing diagnosis: Definitions and classifications. (2009-11 ed.). West-Sussex, UK: Wiley-Blackwell.

Saba, V. K. (2007). Clinical care classification (CCC) system manual: A guide to nursing documentation. New York: Springer Publishing Company.

Schubert, M., Glass, T. R., Clarke, S. P., Aiken, L. H., SchaffertWitvliet, B., Sloane, D. M. et al. (2008). Rationing of nursing care and its relationship to patient outcomes: The Swiss extension of the International Hospital Outcomes Study. International Journal for Quality in Health Care, 20(4), 227-237.

Sermeus, W., Delesie, L., Michiels, D., Van den Heede, K., Van Herck, P., \& Van Landuyt, J. (2006). Actualisatie van de minimale verpleegkundige gegevens: Eindrapport. Leuven, Belgium: Center for Health Services Research, K. U. Leuven.

Sermeus, W., Delesie, L., Van den Heede, K., Diya, L., \& Lesaffre, E. (2008). Measuring the intensity of nursing care: Making use of the Belgian Nursing Minimum Data Set. International Journal of Nursing Studies, 45(7), 1011-1021.

Von Krogh, G., Dale, C., \& Naden, D. (2005). A framework for integrating NANDA, NIC, and NOC terminology in electronic patient records. Journal of Nursing Scholarship, 37(3), 275-281. 